
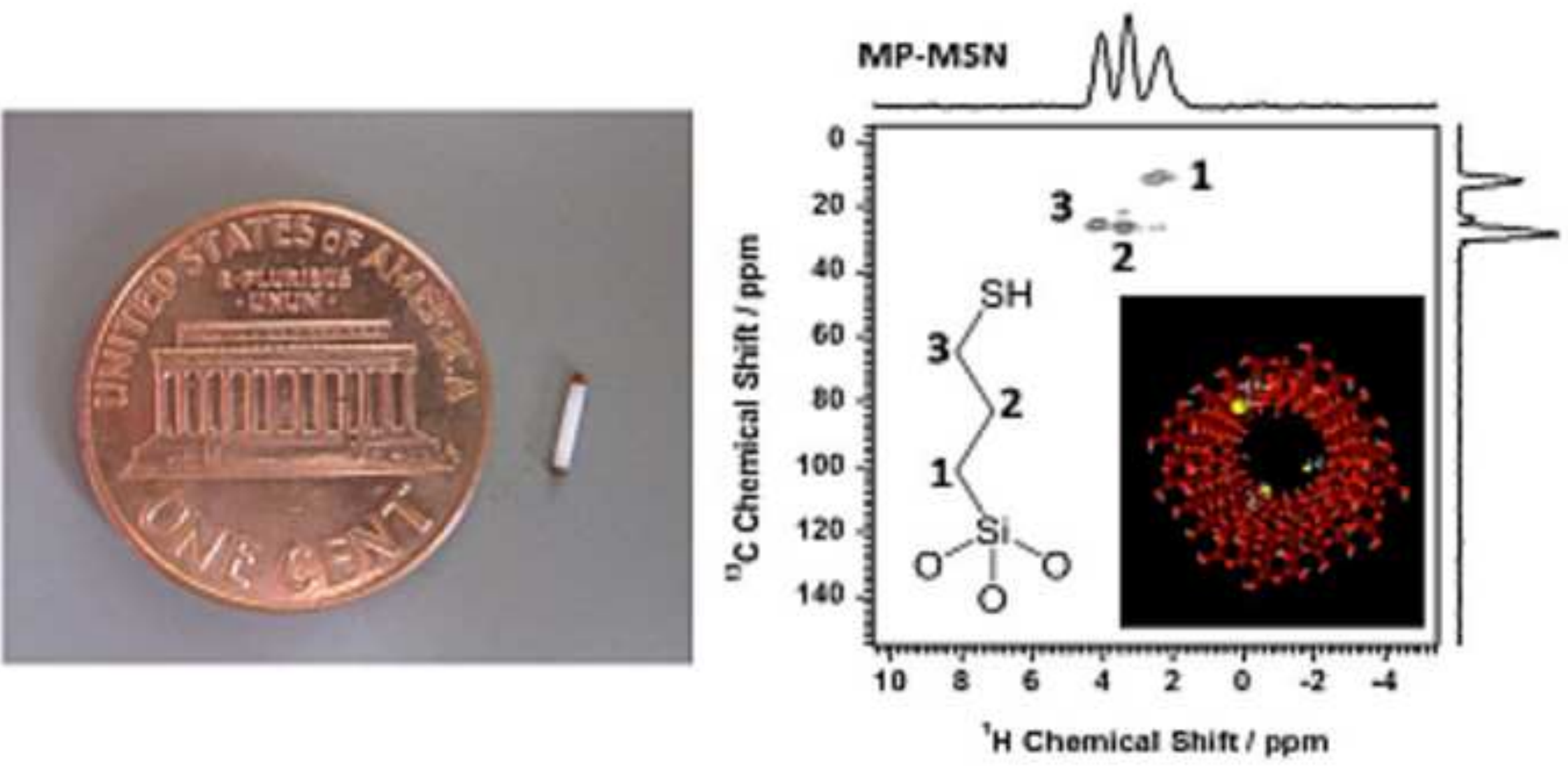


\title{
Studies of minute quantities of natural abundance molecules using 2D heteronuclear correlation spectroscopy under $100 \mathrm{kHz}$ MAS
}

\author{
Y. Nishiyama, ${ }^{\mathrm{a}, \mathrm{b}, *}$ T. Kobayashi, ${ }^{\mathrm{c}}$ M. Malon, ${ }^{\mathrm{a}, \mathrm{b}}$ D. Singappuli-Arachchige, ${ }^{\mathrm{c} d \mathrm{~d}}$ I.I. Slowing, ${ }^{\mathrm{c}, \mathrm{d}}$ M. Pruski ${ }^{\mathrm{c}, \mathrm{d}, *}$ \\ a JEOL Resonance Inc., 3-1-2 Musashino, Akishima, Tokyo 196-8558, Japan \\ ${ }^{\mathrm{b}}$ RIKEN CLST-JEOL Collaboration Center, Yokohama, Kanagawa 230-0045, Japan \\ ${ }^{c}$ U.S. DOE Ames Laboratory, Ames, IA 50011-3020, USA \\ ${ }^{\mathrm{d}}$ Department of Chemistry, Iowa State University, Ames, IA 50011-3020, USA
}

\begin{abstract}
Two-dimensional ${ }^{1} \mathrm{H}\left\{{ }^{13} \mathrm{C}\right\}$ heteronuclear correlation solid-state NMR spectra of naturally abundant solid materials are presented, acquired using the $0.75-\mathrm{mm}$ magic angle spinning (MAS) probe at spinning rates up to $100 \mathrm{kHz}$. In spite of the miniscule sample volume (290 nL), high-quality HSQC-type spectra of bulk samples as well as surface-bound molecules can be obtained within hours of experimental time. The experiments are compared with those carried out at $40 \mathrm{kHz}$ MAS using a 1.6-mm probe, which offered higher overall sensitivity due to a larger rotor volume. The benefits of ultrafast MAS in such experiments include superior resolution in ${ }^{1} \mathrm{H}$ dimension without resorting to ${ }^{1} \mathrm{H}-{ }^{1} \mathrm{H}$ homonuclear $\mathrm{RF}$ decoupling, easy optimization, and applicability to mass-limited samples. The HMQC spectra of surface-bound species can be also acquired under $100 \mathrm{kHz}$ MAS, although the dephasing of transverse magnetization has significant effect on the efficiency transfer under MAS alone.
\end{abstract}

*Corresponding authors.

M. Pruski: Ames Laboratory, Iowa State University, 230 Spedding Hall, Ames, IA 50011-3020, USA. Phone: +1 5152942017 Fax: +1 515294 4709. E-mail address: mpruski@iastate.edu (M. Pruski). Y. Nishiyama: JEOL RESONANCE Inc., 3-1-2 Musashino, Akishima, Tokyo 196-8558, Japan. Fax: +81 42544 1955. E-mail address: yunishiy@jeol.co.jp (Y. Nishiyama). 


\section{INTRODUCTION}

The availability of magic angle spinning (MAS) at ever increasing rates [1-4] has stimulated remarkable progress in the development of solid-state (SS)NMR methods for the studies of a wide range of materials, especially those comprising networks of strongly coupled ${ }^{1} \mathrm{H}$ nuclei. During the last decade, probeheads capable of MAS at $40-60 \mathrm{kHz}$ have become increasingly common in many laboratories, owing their attractiveness to the superb RF capabilities and the ability to average, completely or partially, the anisotropic line-broadening interactions in many solid materials of interest in chemistry, materials science and biology. Multiple studies have highlighted the key advantages of such probeheads, which include excellent sensitivity per spin $[5,6]$, the ability to generate very strong RF magnetic fields, high cross-polarization (CP) efficiency [7, 8], and the possibility of using low-power $\mathrm{RF}$ in schemes requiring prolonged irradiation, e.g., during heteronuclear decoupling or polarization transfer [9-14]. The advent of fast MAS also spearheaded recent progress in the studies of paramagnetic systems, where suppression of large anisotropic paramagnetic broadening and improved decoupling capabilities led to large enhancements of both sensitivity and resolution $[15,16]$. In addition, fast MAS serves to reduce the homonuclear dipolar couplings between high- $\gamma$ nuclei, and is compatible with a number of RF pulse sequences designed for homonuclear ${ }^{1} \mathrm{H}$ decoupling [17-20]. The various combinations of these attributes led to the development of improved pulse sequences for multidimensional correlation studies. Notable examples include the multi-dimensional indirectly detected $\left({ }^{1} \mathrm{H}\right.$-detected or $\left.{ }^{1} \mathrm{H}\{\mathrm{X}\}\right)$ heteronuclear correlation (HETCOR) experiments performed using through-space or through-bond polarization transfers, which offer greatly improved sensitivities compared the previously used X-detected schems [21-24].

Ultrafast MAS, at rates approaching or even exceeding $100 \mathrm{kHz}$, stands to further expand these capabilities. Recent report has shown that the combination of MAS at $90 \mathrm{kHz}$ and amplitude-modulated 
low-power $(12 \mathrm{kHz})$ heteronuclear ${ }^{1} \mathrm{H}$ decoupling produced ${ }^{13} \mathrm{C}$ coherence life time $\left(T_{2}\right)$ for $\mathrm{CH}_{2}$ groups in glycine comparable to that requiring $400 \mathrm{kHz}{ }^{1} \mathrm{H}$ decoupling under slow MAS [4]. Under such conditions, the residual line width of heteronuclei is likely to be governed by other factors, for instance magnetic susceptibility, dynamic effects and local disorder. Since MAS at $100 \mathrm{kHz}$ exceeds the typical ${ }^{1} \mathrm{H}-{ }^{1} \mathrm{H}$ dipolar couplings by a factor of $\sim 2$, CRAMPS-quality ${ }^{1} \mathrm{H}$ resolution can be reached or approached in many solids without the use of RF decoupling [20], further stimulating the advancement and exploitation of multidimensional correlation methods [25-27]. For example, a homonuclear $2 \mathrm{D}{ }^{1} \mathrm{H}-{ }^{1} \mathrm{H}$ double quantum (DQ)MAS correlation spectrum acquired under MAS at $100 \mathrm{kHz}$ yielded correlated distributions of chemical shifts with unforeseen resolution, thereby unraveling the structure of a complex host-guest system [25]. The enhanced ${ }^{1} \mathrm{H}$ resolution and longer $T_{2}$ relaxation times favor the use of heteronuclear correlation methods hitherto limited mainly to solution NMR, including through-bond heteronuclear multiple quantum correlation (HMQC) schemes [26]. Most recently, the benefits of MAS at rates approaching $100 \mathrm{kHz}$ were demonstrated in the study of a sub-milligram quantity of protein, where ${ }^{1} \mathrm{H}$-detected 2D, 3D and 4D experiments utilizing heteronuclear single quantum correlation (HSQC) schemes were used to obtain a de novo structure of isotopically labeled ubiquitin [28].

Here, we demonstrate that despite the miniature rotor size, ultrafast MAS technology can serve to measure $2 \mathrm{D}{ }^{1} \mathrm{H}\left\{{ }^{13} \mathrm{C}\right\}$ HSQC-type spectra of natural abundance materials, even those containing only the surface-bound functionalities. We show that the measurements are easy to optimize, remarkably sensitive, and compare well with those carried out using much larger rotors capable of MAS at $40 \mathrm{kHz}$. In favourable cases, the HMQC-type schemes can be used, as well.

\section{EXPERIMENTAL}


Samples. The well-studied sample of solvent-free, naturally abundant tripeptide (N-formyl-Lmethionyl-L-leucyl-L-phenylalanine, referred to as f-MLF-OH) was chosen because it comprises $\mathrm{CH}$, $\mathrm{CH}_{2}, \mathrm{CH}_{3}$ and quaternary carbon sites, which exhibit a full range of ${ }^{13} \mathrm{C}-{ }^{1} \mathrm{H}$ couplings, from motionally narrowed to those typical of a fully rigid crystal lattice. The sample was purchased from Sigma-Aldrich.

As-MP-MSN, MP-MSN and phenetyl-HMDS-MSN. The organically functionalized mesoporous silica nanoparticles (MSNs) of MCM-41-type were synthesized as reported before [29]. In brief, a mixture of cetyltrimethylammonium bromide (CTAB, $\left.\mathrm{CH}_{3}\left(\mathrm{CH}_{2}\right)_{15} \mathrm{~N}\left(\mathrm{CH}_{3}\right)_{3} \mathrm{Br}\right)(1.0 \mathrm{~g}, 2.7 \mathrm{mmol})$, sodium hydroxide $(3.5 \mathrm{~mL}, 2.0 \mathrm{M})$, and water $(480 \mathrm{~mL})$ was heated to $80^{\circ} \mathrm{C}$ in flask with constant stirring. After one hour, tetraethylorthosilicate (TEOS) $(5.0 \mathrm{~mL}, 23 \mathrm{mmol})$ was added dropwise, which was followed by the addition of substituted trimethoxysilanes (3-mercaptopropyl trimethoxysilane, $1.0 \mathrm{~mL}, 5.1 \mathrm{mmol}$ for MP-MSN, and phenetyl trimethoxysilane, $0.45 \mathrm{~mL}, 2.1 \mathrm{mmol}$ for phenetyl-MSN). The mixtures were vigorously stirred at $80^{\circ} \mathrm{C}$ for 2 hours and filtered. The resulting white solids were washed with copious amount of water and methanol and dried under vacuum overnight, yielding the as-synthesized materials as-MP-MSN and as-phenetyl-MSN.

To remove the surfactant template, $1.0 \mathrm{~g}$ of as-MP-MSN or as-phenetyl-MSN was suspended in methanol $(100 \mathrm{~mL})$, concentrated $\mathrm{HCl}$ was added $(1.0 \mathrm{~mL})$ and the mixture was refluxed for $6 \mathrm{~h}$. The solid was then recovered by filtration and washed with copious amounts of water and methanol, and then dried under vacuum overnight. The extracted materials are referred to as MP-MSN and phenetylMSN.

Textural properties of these materials were measured by nitrogen sorption isotherms at $-196{ }^{\circ} \mathrm{C}$ in a Micromeritics Tristar analyzer. The surface areas were calculated by the Brunauer-Emmett-Teller (BET) method, and the pore size distribution was calculated by the Barrett-Joyner-Halenda (BJH) method. Pretreatment of samples for surface area measurement was done by flowing $\mathrm{N}_{2}$ for $6 \mathrm{~h}$ at $100{ }^{\circ} \mathrm{C}$. MP- 
MSN had a surface area of $980 \mathrm{~m}^{2} / \mathrm{g}, 2.2 \mathrm{~nm}$ pore width and a pore volume of $0.54 \mathrm{~cm}^{3} / \mathrm{g}$; the corresponding values for phenethyl-MSN were $1149 \mathrm{~m}^{2} / \mathrm{g}, 2.45 \mathrm{~nm}$ and $1.07 \mathrm{~cm}^{3} / \mathrm{g}$.

The loading of organic groups in MP-MSN was determined with the Perkin Elmer 2100 Series II CHN/S Elemental Analyzer, using acetanilide as a standard, and combustion and reduction at $925{ }^{\circ} \mathrm{C}$ and $640{ }^{\circ} \mathrm{C}$. The amount of mercaptopropyl groups in MP-MSN was found to be $2.45 \mathrm{mmol} / \mathrm{g}$.

Phenetyl-MSN (0.4 g) was further reacted with hexamethyldisilazane (HMDS) (2.0 mL, 9.6 mmol) by refluxing in hexanes $(100 \mathrm{~mL})$ for $24 \mathrm{~h}$. The final product (phenethyl-HMDS-MSN) was recovered by filtration, washed with copious amounts of hexanes, and dried under vacuum overnight.

Solid-state NMR measurements. All measurements were performed at 14.1 T, on a JEOL ECA600 spectrometer $\left(0.75-\mathrm{mm}\right.$ probe, operated at a MAS rate $\left.v_{\mathrm{R}}=90-100 \mathrm{kHz}\right)$ and a $600 \mathrm{MHz}$ Varian NMR System spectrometer (1.6-mm probe, $v_{\mathrm{R}}=40-42 \mathrm{kHz}$ ). Basic sensitivity tests were performed using 1D MAS spectra measured under direct polarization (DPMAS). The 2D pulse sequences followed the HSQC and HMQC schemes used in solution NMR [30, 31], with various modifications specific to solids (Fig. 1) [20-23]. In both experiments, the ${ }^{13} \mathrm{C}$ magnetization evolving during $t_{1}$ under the isotropic chemical shift is transferred to ${ }^{1} \mathrm{H}$ nuclei and subsequently detected during $t_{2}$. As a reference, we also carried out a ${ }^{13} \mathrm{C}$-detected experiment using a 1.6-mm probe, where PMLG homonuclear ${ }^{1} \mathrm{H}-{ }^{1} \mathrm{H}$ decoupling was applied during $t_{1}$ to maximize the ${ }^{1} \mathrm{H}$ resolution (pulse sequence not shown) $[17,18,32]$.

As detailed below, the sequences used double-quantum (DQ) or zero-quantum (ZQ) Hartmann-Hahn CP conditions [33], and CW, SPINAL-64 or WALTZ heteronuclear decoupling [34, 35], as appropriate, using low RF magnetic fields of $\sim v_{\mathrm{R}} / 4$ or less. The uncorrelated ${ }^{1} \mathrm{H}$ magnetization has been purged during the HORROR recoupling period, as reported earlier [36, 37]. The HORROR condition was established by minimizing the ${ }^{1} \mathrm{H}$ NMR signal following a spin-locking pulse, first by setting the spinlock RF magnetic field strength at $\sim \nu_{\mathrm{R}} / 2$, then by optimizing the duration of the spin-locking pulse $\tau_{\mathrm{RR}}$. 
States-TPPI quadrature detection was used by switching appropriately the phase of the first $\pi / 2$ pulse in the ${ }^{13} \mathrm{C}$ channel.

The experimental parameters are given in the figure captions, using the following symbols: $v_{R}$ indicates the sample rotation rate, ${ }_{\mathrm{RF}}^{\mathrm{X}}$ the magnitude of $\mathrm{RF}$ magnetic field at the frequency of $\mathrm{X}$ nuclei, $\tau_{\mathrm{CP} 1}$ the $\mathrm{CP}$ time for the first $\left({ }^{1} \mathrm{H} \rightarrow{ }^{13} \mathrm{C}\right)$ polarization transfer, $\tau_{\mathrm{CP} 2}$ the $\mathrm{CP}$ time for the second $\left({ }^{13} \mathrm{C} \rightarrow{ }^{1} \mathrm{H}\right)$ polarization transfer, $\tau_{\mathrm{RR}}$ is the rotary resonance recoupling period, $\tau_{\mathrm{RD}}$ the recycle delay, $\Delta t_{1}$ the time increment during $t_{1}$ evolution, NS the number of scans, and AT the total acquisition time. All spectra were recorded using purge gas, with the rotor temperature increased above the ambient by $\sim 15^{\circ} \mathrm{C}$ at $\nu_{\mathrm{R}}$ $=40 \mathrm{kHz}$ and by $\sim 30{ }^{\circ} \mathrm{C}$ at $\nu_{\mathrm{R}}=100 \mathrm{kHz}$. The proton and carbon chemical shifts $\delta_{\mathrm{H}}$ and $\delta_{\mathrm{C}}$ are referenced to TMS at $0 \mathrm{ppm}$.

(a)

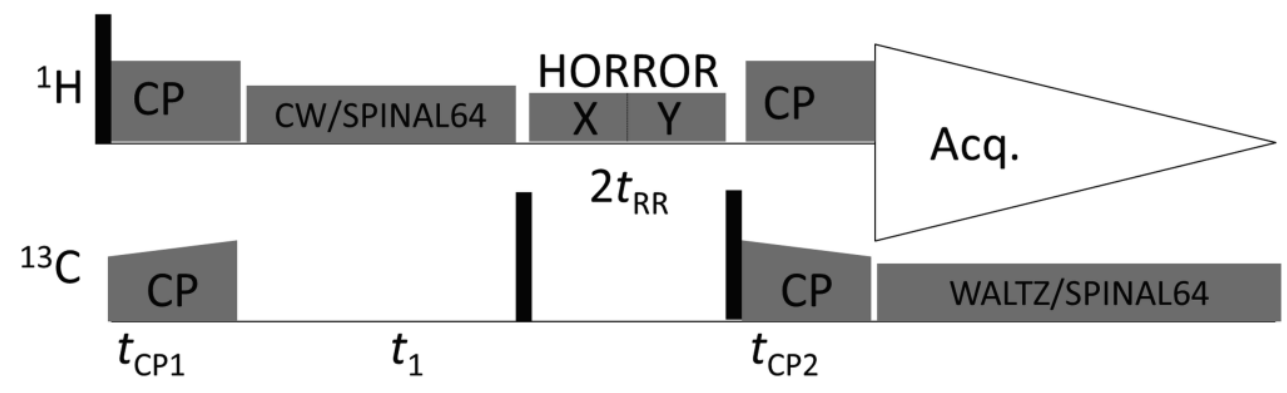

(b)

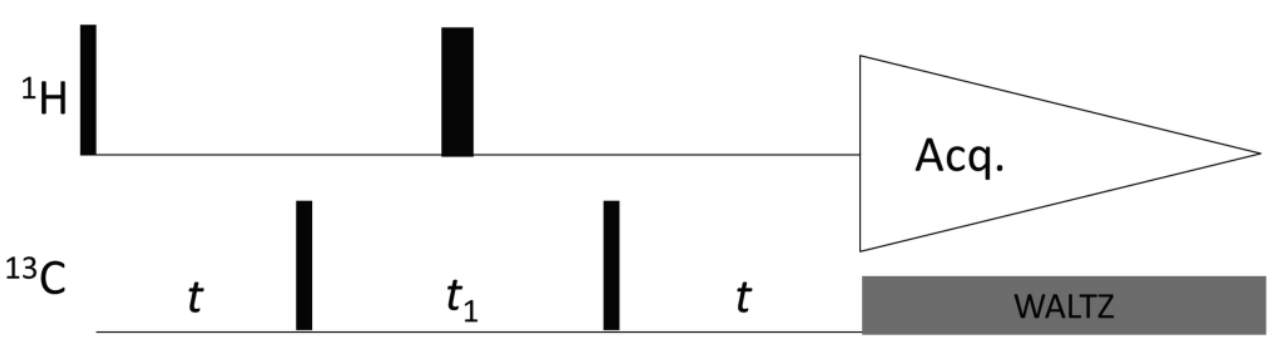

Fig. 1. (A) CP-based HSQC-type and (B) HMQC pulse sequences used in this study. In the HSQC measurements, ${ }^{1} \mathrm{H}$ magnetization is transferred to ${ }^{13} \mathrm{C}$ spins followed by ${ }^{13} \mathrm{C}$ free precession under lowpower $\mathrm{CW}$ or SPINAL-64 ${ }^{1} \mathrm{H}$ decoupling during the $t_{1}$ period. The residual ${ }^{1} \mathrm{H}$ magnetization is suppressed by phase-altered HORROR irradiation during $\tau_{\mathrm{RR}}$. The evolution of ${ }^{13} \mathrm{C}$ magnetization is observed indirectly after the second $\mathrm{CP}$ transfer, via ${ }^{1} \mathrm{H}$ precession under WALTZ or SPINAL-64 ${ }^{13} \mathrm{C}$ decoupling. 


\section{RESULTS AND DISCUSSION}

\section{Optimization of $2 D$ measurements}

0.75-mm MAS probe. The experimental conditions were optimized by observing NMR spectra of ${ }^{13} \mathrm{C}_{3},{ }^{15} \mathrm{~N}$-L-alanine. It has been our experience that $\mathrm{CP}$ transfers under DQ Hartmann-Hahn matching condition

$$
\underset{\mathrm{RF}}{\mathrm{H}}+\stackrel{\mathrm{C}}{\mathrm{RF}}=n_{\mathrm{R}}
$$

yielded slightly better signal intensities (by a few percent in our tests) than the traditional ZQCP format

$$
\begin{array}{ll}
\mathrm{H} & \mathrm{C} \\
\mathrm{RF} & \mathrm{RF}
\end{array}= \pm n_{\mathrm{R}} .
$$

Additionally, the use of weaker RF magnetic field lessens the burden of high-power on the NMR probe and lowers the risk of overheating the sample. Thus, the DQCP matching condition has been used in all our experiments utilizing the $0.75-\mathrm{mm}$ probe.

The DQCP conditions for both $\mathrm{CP} 1$ and $\mathrm{CP} 2$ proved easy to optimize using the following procedure. First, we roughly maximized the ${ }^{1} \mathrm{H} \rightarrow{ }^{13} \mathrm{C}$ CP transfer with $\tau_{\mathrm{CP}}=2 \mathrm{~ms}$, by adjusting $\underset{\mathrm{RF}}{\mathrm{H}}$ and ${ }_{\mathrm{RF}}^{\mathrm{C}}$

(including ramp in the ${ }^{13} \mathrm{C}$ channel). As a general rule, we used $\underset{\mathrm{RF}}{\mathrm{C}}>\underset{\mathrm{RF}}{\mathrm{H}}$ to cover the broader ${ }^{13} \mathrm{C}$ chemical shift range. Specifically, two DQCP conditions were targeted, referred to as DQH30 (where $\underset{\mathrm{RF}}{\mathrm{H}}=30 \mathrm{kHz}$ and $\quad \underset{\mathrm{RF}}{\mathrm{C}}=70 \mathrm{kHz})$ and DQH10 $\left(\begin{array}{l}\mathrm{H} \\ \mathrm{RF}\end{array}=10 \mathrm{kHz}\right.$ and $\left.\underset{\mathrm{RF}}{\mathrm{C}}=90 \mathrm{kHz}\right)$. Subsequently, the $\mathrm{CP} 1$ and $\mathrm{CP} 2$ conditions were fine-tuned, including the sense of ramp, by monitoring ${ }^{1} \mathrm{H}$ signal intensities using the sequence shown in Fig. $1 \mathrm{~A}$ with $t_{1}=0$. We used DQH30 condition with $\tau_{\mathrm{CP} 1}=2 \mathrm{~ms}$ to attain optimal efficiency and uniformity of $\mathrm{CP} 1\left({ }^{1} \mathrm{H} \rightarrow{ }^{13} \mathrm{C}\right)$ polarization transfer. On the other hand, the $\mathrm{DQH} 10$ condition with short $\tau_{\mathrm{CP} 2}$ value of 0.2 to $0.4 \mathrm{~ms}$ is preferred for $\mathrm{CP} 2$ to enhance the selectivity of magnetization transfer between bonded ${ }^{1} \mathrm{H}^{13} \mathrm{C}$ pairs. Under ultrafast MAS the heteronuclear dipolar interactions between bonded ${ }^{1} \mathrm{H}-{ }^{13} \mathrm{C}$ pairs dominate the spin dynamics during ${ }^{13} \mathrm{C}$ - 
${ }^{1} \mathrm{H} \mathrm{CP}$, leading to fast and efficient polarization build-up (with the first maximum at $\sim 70 \mu \mathrm{s}[38]$ ) and strong truncation of long-range transfers. We finally note that in the presence of ${ }^{13} \mathrm{C}$ and ${ }^{1} \mathrm{H}$ resonance offsets, $\quad{ }_{\mathrm{RF}}^{\mathrm{C}}$ and $\quad{ }_{\mathrm{RF}}^{\mathrm{H}}$, the DQCP Hartmann-Hahn with $n=1$ can be written as

$$
\sqrt{\left(\begin{array}{c}
\mathrm{H} \\
\mathrm{RF}
\end{array}\right)^{2}+\left(\begin{array}{c}
\mathrm{H} \\
0
\end{array}\right)^{2}}+\sqrt{\left(\begin{array}{c}
\mathrm{C} \\
\mathrm{RF}
\end{array}\right)^{2}+\left(\begin{array}{c}
\mathrm{C} \\
0
\end{array}\right)^{2}}=\mathrm{R}
$$

Although we did not carry out systematic measurements of CP efficiencies as a function of ${ }_{\mathrm{RF}}^{\mathrm{C}}$, it is advisable to place the ${ }^{13} \mathrm{C}$ carrier frequency near the center of the spectrum, in addition to using the ramped $\mathrm{CP}$ schemes, to maximize the uniformity of polarization transfers.

1.6-mm MAS probe. The 2D HETCOR experiments performed at $v_{\mathrm{R}}=40$ or $41.667 \mathrm{kHz}$ used tangent $\mathrm{CP} 1$ and $\mathrm{CP} 2$ transfers, with $\quad \underset{\mathrm{RF}}{\mathrm{H}}$ and $\underset{\mathrm{RF}}{\mathrm{C}}$ of around $60 \mathrm{kHz}$ and $100 \mathrm{kHz}$, respectively.

\section{Results}

Sensitivity of $1 D$ DPMAS. To estimate of the relative sensitivity in experiments carried out with 1.6mm and 0.75-mm MAS probes, we measured 1D DPMAS spectra of hexamethylbenzene. The spectra were acquired using fully loaded rotors, under equivalent conditions, including the MAS rate (40 kHz). The measurements (not shown), yielded the $\mathrm{S} / \mathrm{N}$ ratios that differed by a factor of $\sim 12$ in favor of the larger rotor.

This outcome is not unexpected: the overall loss of signal due to smaller samples size is only partly offset by higher sensitivity per unit volume. At a given magnetic field and temperature, the signal to noise $(\mathrm{S} / \mathrm{N})$ ratio of a small-size coil is proportional to [39]

$$
S / N \frac{B_{1} V}{\sqrt{R_{\text {coil }}}},
$$

where $V$ is the sample volume, $R_{\text {coil }}$ denotes the coil resistance due to conducting losses as well as skin and proximity effects, and $B_{1}$ is the magnitude of the transverse RF magnetic field induced in the coil by a unit current, which in a single-layer solenoid coil is determined by the coil length $l$, coil diameter $d_{\text {coil, }}$ 
and the number of turns $m$ [40],

$$
B_{1} \frac{m}{d_{\text {coil }} \sqrt{1+\left(l / d_{\text {coil }}\right)^{2}}} \text {. }
$$

Despite their small size, both coils used in our experiments operate in the skin depth regime (the skin depth of copper is a few $\mu \mathrm{m}$ at the frequencies of our interest), where

$$
R_{\text {coil }} \frac{m^{2} d_{\text {coil }}}{l}
$$

From (4), (5) and (6) it follows that for coils with the same value of $l / d_{\text {coil }}$ the dependency of $\mathrm{S} / \mathrm{N}$ ratio per unit volume should scale as $\left(d_{\text {coil }}\right)^{1}$.

In the abovementioned DPMAS measurements of hexamethylbenzene, the spectra were acquired with $d_{\text {coil }} \cong 1.2 \mathrm{~mm}$ and the active sample volume of $V=290 \mathrm{~nL}(0.75-\mathrm{mm}$ probe $)$, and $d_{\text {coil }} \cong 2.2 \mathrm{~mm}$ and $V \cong 6 \mu \mathrm{L}$ (1.6-mm probe). Disregarding possible differences in the receiver noise levels in JEOL and Varian spectrometers, RF magnetic field inhomogeneities, probe circuit design, sample packing, sample heating, etc., and considering only the product of sample volume and relative sensitivity, should give a factor of $(6000 / 290) /(2.2 / 1.2) \cong 11$ in favor of a larger rotor, which indeed agrees very well with the result of our measurement. Thus, in standard in 1D experiments the use of ultrafast MAS imposes a severe penalty on sensitivity. However, this technology will be applicable in experiments requiring high ${ }^{1} \mathrm{H}$ resolution (especially ${ }^{1} \mathrm{H}$-detected HETCOR), very high RF fields, or for samples with limited mass.

2D HETCOR spectra of MLF. In Figs. 2A-C, we compare 2D ${ }^{1} \mathrm{H}^{13} \mathrm{C}$ HETCOR spectra of f-MLF$\mathrm{OH}$ tripeptide taken under the following conditions: $(\mathrm{A}){ }^{1} \mathrm{H}\left\{{ }^{13} \mathrm{C}\right\}, v_{\mathrm{R}}=100 \mathrm{kHz}, \tau_{\mathrm{CP} 1}=2 \mathrm{~ms}$, and $\tau_{\mathrm{CP} 2}=$ $0.4 \mathrm{~ms}$ (referred to as DQH30_2ms_DQH10_0.4ms); (B) ${ }^{1} \mathrm{H}\left\{{ }^{13} \mathrm{C}\right\}, v_{\mathrm{R}}=41,667 \mathrm{kHz}, \tau_{\mathrm{CP} 1}=2 \mathrm{~ms}$, and $\tau_{\mathrm{CP} 2}=0.4 \mathrm{~ms}$; and $(\mathrm{C}){ }^{13} \mathrm{C}\left\{{ }^{1} \mathrm{H}\right\}$ (note that this is a ${ }^{13} \mathrm{C}$-detected spectrum), $\nu_{\mathrm{R}}=41,667 \mathrm{kHz}$, and $\tau_{\mathrm{CP}}=$ $0.4 \mathrm{~ms}$. All spectra were optimized as explained above and acquired under similar experimental 
conditions in $5 \mathrm{~h}(\mathrm{~A})$ and $10 \mathrm{~h}(\mathrm{~B}, \mathrm{C})$. A complete list of acquisition parameters is given in the figure caption. The peaks assignments are shown in Table 1 and Scheme 1, based on the earlier studies by Griffin et al. [41, 42]. We observe that there are some notable differences between relative peak intensities in the spectra in Fig. 2 due to various efficiencies of ${ }^{1} \mathrm{H} \rightarrow{ }^{13} \mathrm{C}$ and ${ }^{13} \mathrm{C} \rightarrow{ }^{1} \mathrm{H} \mathrm{CP}$ transfers in our experiments. They are most significant for the carbonyl groups, which were clearly detected under 100 $\mathrm{kHz}$ MAS using $\tau_{\mathrm{CP} 2}=2 \mathrm{~ms}$ (DQH30_2ms_DQH10_2ms, spectrum not shown), and phenyl rings, which are known to undergo $180^{\circ}$ flips at a rate of $\sim 10^{5} \mathrm{~s}^{-1}$ [42], and are essentially absent in the spectra acquired at $100 \mathrm{kHz}$ MAS.

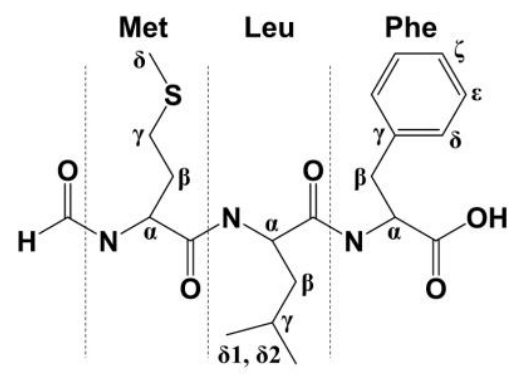

Scheme 1. Molecular structure of f-MFL-OH.

Notwithstanding these differences, an estimate of the $\mathrm{S} / \mathrm{N}$ ratios in the spectra of Figs. $2 \mathrm{~A}$ and $2 \mathrm{~B}$ indicates that the relative sensitivity adjusted for the number of scans is on average only about 1-2 times better in spectrum (B), which represents a considerable shift in favor of the $0.75-\mathrm{mm}$ probe compared to 1D DPMAS spectra. This notable result can be mostly attributed to improved resolution in the ${ }^{1} \mathrm{H}$ dimension at $100 \mathrm{kHz}$ MAS (here, by a factor of approximately 2) and, to a lesser extent, in the ${ }^{13} \mathrm{C}$ dimension (here, on average by $20 \%$ ).

Another factor affecting the observed sensitivities, albeit difficult to quantify precisely, is that the electronic circuit of the $0.75-\mathrm{mm}$ probe was optimized for ${ }^{1} \mathrm{H}$ detection. We can only note that the JEOL 0.75-mm probe delivered $\begin{aligned} & \mathrm{H} \\ & \mathrm{RF}\end{aligned}=490 \mathrm{kHz}$ at $60 \mathrm{~W}$ power, and $\underset{\mathrm{RF}}{\mathrm{C}}=221 \mathrm{kHz}$ at $100 \mathrm{~W}$ power. For the Varian 1.6-mm probe, the corresponding values are $\underset{\mathrm{RF}}{\mathrm{H}}=235 \mathrm{kHz}$ and $\underset{\mathrm{RF}}{\mathrm{C}}=177 \mathrm{kHz}$. 
We also acquired a ${ }^{13} \mathrm{C}$-detected spectrum with PMLG homonuclear ${ }^{1} \mathrm{H}-{ }^{1} \mathrm{H}$ decoupling during the ${ }^{1} \mathrm{H}$ evolution period $t_{1}$ (Fig. 2C). The resulting spectrum exhibits state-of-the-art resolution, which slightly exceeds one delivered by MAS at $100 \mathrm{kHz}$. However, the ${ }^{13} \mathrm{C}\left\{{ }^{1} \mathrm{H}\right\}$ HETCOR experiment lacks the sensitivity benefit of ${ }^{1} \mathrm{H}$-detection, and in effect yields similar sensitivity per unit time than the ${ }^{1} \mathrm{H}\left\{{ }^{13} \mathrm{C}\right\}$ measurement in Fig. 2A, which further underscores the merit of ultrafast MAS. Another important fact to note is that in accordance with our earlier comments, the only correlations observed in Fig. 2A are those between directly bonded ${ }^{1} \mathrm{H}^{-13} \mathrm{C}$ pairs. This is in contrast to a spectrum reported in our earlier study, where at $\nu_{\mathrm{R}}=41.667 \mathrm{kHz}$ and $\tau_{\mathrm{CP} 2}=0.3 \mathrm{~ms}$ multiple long-range correlations were observed [32]. Most likely, ultrafast MAS significantly reduced ${ }^{1} \mathrm{H}-{ }^{1} \mathrm{H}$ couplings and accordingly the long-range ${ }^{1} \mathrm{H}-{ }^{13} \mathrm{C}$ correlations during the $\mathrm{CP} 2$ period, producing a spectrum similar to $J$-based schemes. Further study will help to understand the behavior of long-range ${ }^{1} \mathrm{H}_{-}{ }^{13} \mathrm{C}$ correlations under ultrafast MAS.
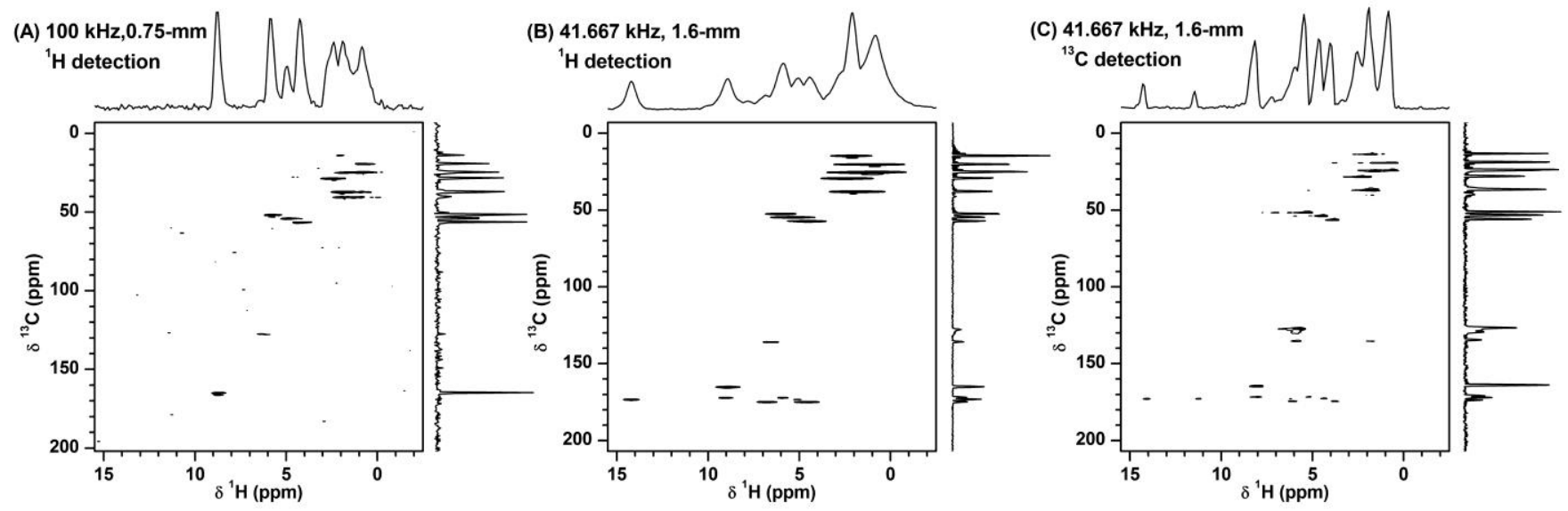

Fig. 2. 2D ${ }^{1} \mathrm{H}^{13}{ }^{13} \mathrm{C}$ HSQC-type spectra of f-MLF-OH taken at $14.1 \mathrm{~T}$ under the following conditions: (A) ${ }^{1} \mathrm{H}\left\{{ }^{13} \mathrm{C}\right\}, v_{\mathrm{R}}=100 \mathrm{kHz}, \tau_{\mathrm{CP} 1}=2 \mathrm{~ms}, \tau_{\mathrm{CP} 2}=0.4 \mathrm{~ms},\left(\mathrm{DQH} 30 \_2 \mathrm{~ms} \_\mathrm{DQH} 10 \_0.4 \mathrm{~ms}\right), \tau_{\mathrm{RR}}=10 \mathrm{~ms}, \quad{ }_{\mathrm{RF}}^{\mathrm{H}}=$ $10 \mathrm{kHz}$ during $\mathrm{CW}{ }^{1} \mathrm{H}$ decoupling, ${ }_{\mathrm{RF}}^{\mathrm{H}}=50 \mathrm{kHz}$ during $\tau_{\mathrm{RR}}$, and ${ }_{\mathrm{RF}}^{\mathrm{C}}=10 \mathrm{kHz}$ during WALTZ ${ }^{13} \mathrm{C}$ decoupling; (B) ${ }^{1} \mathrm{H}\left\{{ }^{13} \mathrm{C}\right\}, \nu_{\mathrm{R}}=41,667 \mathrm{kHz}, \tau_{\mathrm{CP} 1}=2 \mathrm{~ms}, \tau_{\mathrm{CP} 2}=0.4 \mathrm{~ms}, \tau_{\mathrm{RR}}=40 \mathrm{~ms}, \quad{ }_{\mathrm{RF}}^{\mathrm{H}} \approx 60 \mathrm{kHz}$ during tangent $\tau_{\mathrm{CP} 1}$ and $\tau_{\mathrm{CP} 2}, \quad{ }_{\mathrm{RF}}^{\mathrm{H}}=10 \mathrm{kHz}$ during SPINAL-64 ${ }^{1} \mathrm{H}$ decoupling, $\quad{ }_{\mathrm{RF}}^{\mathrm{H}}=20.85 \mathrm{kHz}$ during $\tau_{\mathrm{RR}}, \quad{ }_{\mathrm{RF}}^{\mathrm{C}}=102 \mathrm{kHz}$ during $\tau_{\mathrm{CP} 1}$ and $\tau_{\mathrm{CP} 2}$, and ${ }_{\mathrm{RF}}^{\mathrm{C}}=10 \mathrm{kHz}$ during SPINAL-64 ${ }^{13} \mathrm{C}$ decoupling; and (C) ${ }^{13} \mathrm{C}\left\{{ }^{1} \mathrm{H}\right\}, \quad v_{\mathrm{R}}=41,667 \mathrm{kHz}, \tau_{\mathrm{CP}}=0.4 \mathrm{~ms}, \quad \underset{\mathrm{RF}}{\mathrm{H}} \approx 64 \mathrm{kHz}$ during tangent $\tau_{\mathrm{CP}}, \quad{ }_{\mathrm{RF}}^{\mathrm{H}}=10 \mathrm{kHz}$ during SPINAL-64 ${ }^{1} \mathrm{H}$ decoupling, $\underset{\mathrm{RF}}{\mathrm{C}}=106 \mathrm{kHz}$ during $\tau_{\mathrm{CP}}$, and $\underset{\mathrm{RF}}{\mathrm{C}}=10 \mathrm{kHz}$ during SPINAL-64 ${ }^{13} \mathrm{C}$ 
decoupling. In addition PMLG decoupling with $\underset{\mathrm{RF}}{\mathrm{H}} \approx 160 \mathrm{kHz}$ was used during $t_{1}$ in $(\mathrm{C})$. All spectra were acquired in 256 rows with $\Delta t_{1}=24 \mu \mathrm{s}$ and $\tau_{\mathrm{RD}}=2.25 \mathrm{~s}$. In $(\mathrm{A})$, the number of scans per raw was $\mathrm{NS}=16$, resulting in $\mathrm{AT} \approx 5 \mathrm{~h}$, while in $(\mathrm{B})$ and $(\mathrm{C})$ the acquisition time was increased twofold to NS = 32 and $\mathrm{AT} \approx 10 \mathrm{~h}$. The spectra were processed using the same parameters and are accompanied by equivalent ${ }^{1} \mathrm{H}$ and ${ }^{13} \mathrm{C}$ skyline projections.

Table 1 The spectral assignments in f-MLF-OH.

\begin{tabular}{|c|c|c|c|c|c|}
\hline & $\delta_{\mathrm{C}}[\mathrm{ppm}]$ & & $\delta_{\mathrm{C}}[\mathrm{ppm}]$ & & $\delta_{\mathrm{C}}[\mathrm{ppm}]$ \\
\hline $\mathbf{M}^{\alpha}$ & 52.0 & $\mathrm{~L}^{\alpha}$ & 56.8 & $\mathrm{~F}^{\alpha}$ & 54.3 \\
\hline $\mathrm{M}^{\beta}$ & 37.5 & $L^{\beta}$ & 40.6 & $F^{\beta}$ & 36.9 \\
\hline $\mathbf{M}^{\gamma}$ & 28.7 & $\mathrm{~L}^{\gamma}$ & 25.0 & $\mathrm{~F}^{\gamma}$ & $\sim 130^{\mathrm{a}}$ \\
\hline $\mathrm{M}^{\delta}$ & 14.0 & $L^{\delta 1}$ & 24.6 & $\mathrm{~F}^{\delta}$ & $\sim 130^{\mathrm{a}}$ \\
\hline $\mathbf{M}^{\text {carbonyl }}$ & 172.1 & $\mathrm{~L}^{\delta 1}$ & 19.6 & $F^{\varepsilon}$ & $\sim 130^{\mathrm{a}}$ \\
\hline $\mathrm{M}^{\text {formyl }}$ & 165.2 & $\mathrm{~L}^{\text {carbonyl }}$ & 174.8 & $\mathrm{~F}^{\zeta}$ & 127.6 \\
\hline & & & & $\mathrm{F}^{\text {carboxyl }}$ & 173.2 \\
\hline
\end{tabular}

${ }^{\mathrm{a}}$ unresolved due to ring dynamics

2D HETCOR spectra of MSNs. The ${ }^{1} \mathrm{H}\left\{{ }^{13} \mathrm{C}\right\}$ HSQC spectra of MP-MSN acquired using 0.75-mm and 1.6-mm probes (here at $v_{\mathrm{R}}=90 \mathrm{kHz}$ and $=40 \mathrm{kHz}$, respectively) are shown in Fig. 3A and 3B. Based on the ${ }^{13} \mathrm{C}$ spectra published in our earlier study [43], the main observed cross-peaks are ascribed to $\mathrm{Si}-\boldsymbol{C H}_{2}-\mathrm{CH}_{2}-\mathrm{CH}_{2}-\mathrm{SH}$ (a), $\mathrm{Si}-\mathrm{CH}_{2}-\boldsymbol{C H}_{2}-\mathrm{CH}_{2}-\mathrm{SH}$ (b), and $\mathrm{Si}-\mathrm{CH}_{2}-\mathrm{CH}_{2}-\boldsymbol{C H}_{2}-\mathrm{SH}$ (c) in $\mathrm{MP}$ groups. Here the resolution is not affected by MAS, and the sensitivity per scan is estimated at $\sim 1 / 5$ of that of the 'larger' 1.6-mm probe. According to the elemental analysis, the MP-MSN material contained 2.45 $\mathrm{mmol} / \mathrm{g}$ of natural abundance MP functional groups bound to the silica surface. Thus, the spectrum in Fig. 3A was derived from just about $10^{16}$ pairs of ${ }^{13} \mathrm{C}-{ }^{1} \mathrm{H}$ nuclei decorating roughly $0.25 \mathrm{~m}^{2}$ of silica surface. Remarkably, a similar 2D HETCOR spectrum could be detected from just $25 \mathrm{~cm}^{2}$ of silica surface by using ${ }^{13} \mathrm{C}$-enrichment. 

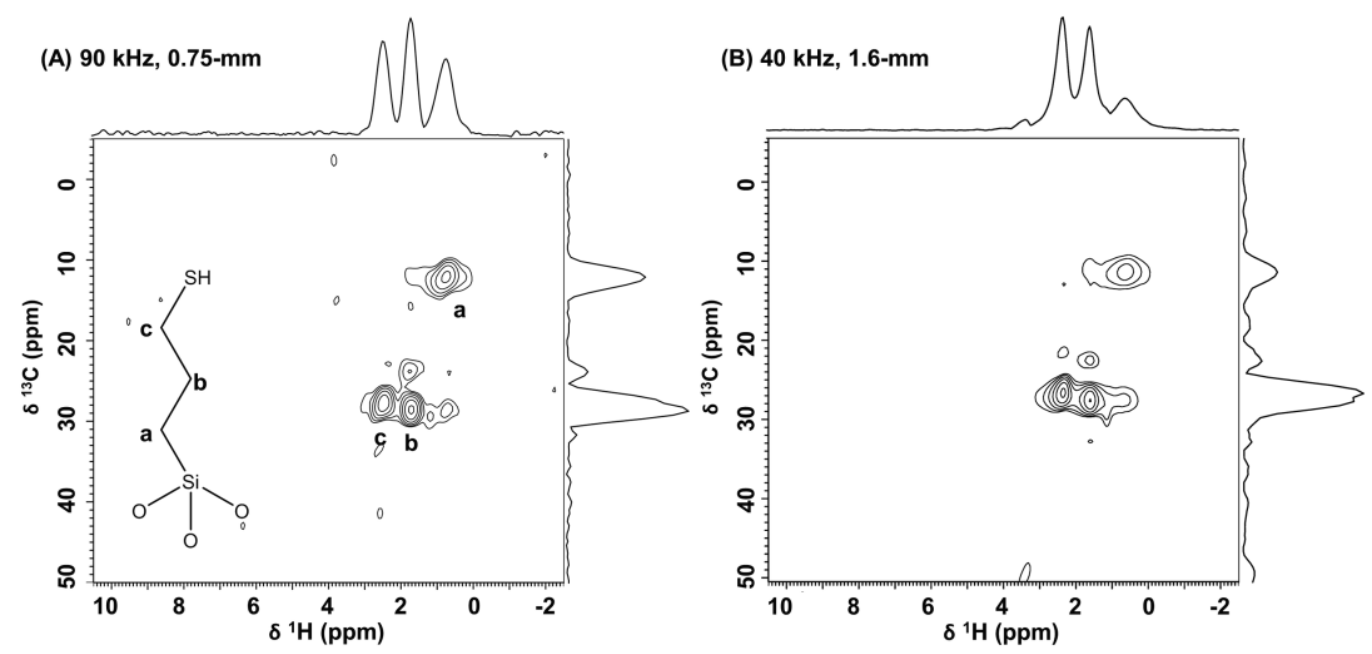

Fig. 3. 2D ${ }^{1} \mathrm{H}-{ }^{13} \mathrm{C}$ HSQC-type spectra of MP-MSN taken at $14.1 \mathrm{~T}$ under the following conditions: (A) ${ }^{1} \mathrm{H}\left\{{ }^{13} \mathrm{C}\right\}, \nu_{\mathrm{R}}=90 \mathrm{kHz} ; \tau_{\mathrm{CP} 1}=\tau_{\mathrm{CP} 2}=2 \mathrm{~ms}\left(\mathrm{DQH} 30 \_2 \mathrm{~ms} \_\mathrm{DQH} 30 \_2 \mathrm{~ms}\right), \tau_{\mathrm{RR}}=10 \mathrm{~ms}, \quad{ }_{\mathrm{RF}}^{\mathrm{H}}=10 \mathrm{kHz}$ during $\mathrm{CW}{ }^{1} \mathrm{H}$ decoupling, $\quad{ }_{\mathrm{RF}}^{\mathrm{H}}=45 \mathrm{kHz}$ during $\tau_{\mathrm{RR}}, \quad{ }_{\mathrm{RF}}^{\mathrm{C}}=10 \mathrm{kHz}$ during WALTZ ${ }^{13} \mathrm{C}$ decoupling; (B) ${ }^{1} \mathrm{H}\left\{{ }^{13} \mathrm{C}\right\}, \nu_{\mathrm{R}}=40 \mathrm{kHz} ; \tau_{\mathrm{CP} 1}=\tau_{\mathrm{CP} 2}=2 \mathrm{~ms}, \tau_{\mathrm{RR}}=40 \mathrm{~ms}, \quad \stackrel{\mathrm{H}}{\mathrm{RF}}=60 \mathrm{kHz}$ during tangent $\tau_{\mathrm{CP} 1}$ and $\tau_{\mathrm{CP} 2}, \quad{ }_{\mathrm{RF}}^{\mathrm{H}}$ $=10 \mathrm{kHz}$ during SPINAL-64 ${ }^{1} \mathrm{H}$ decoupling, $\quad \underset{\mathrm{RF}}{\mathrm{H}}=20 \mathrm{kHz}$ during $\tau_{\mathrm{RR}}, \quad \stackrel{\mathrm{RF}}{\mathrm{C}}=100 \mathrm{kHz}$ during $\tau_{\mathrm{CP} 1}$ and $\tau_{\mathrm{CP} 2}$, and ${ }_{\mathrm{RF}}^{\mathrm{C}}=10$ during SPINAL-64 ${ }^{13} \mathrm{C}$ decoupling. Spectrum (A) was acquired in 64 rows, with $\Delta t_{1}$ $=26.5 \mu \mathrm{s}, 384$ scans per row, $\tau_{\mathrm{RD}}=1 \mathrm{~s}$, and $\mathrm{AT}=13.7 \mathrm{~h}$. Spectrum $(\mathrm{B})$ was acquired in 64 rows, with $\Delta t_{1}=25 \mu \mathrm{s}$, 96 scans per row, $\tau_{\mathrm{RD}}=1 \mathrm{~s}$, and $\mathrm{AT}=3.8 \mathrm{~h}$. The spectra were processed using the same parameters and are accompanied by equivalent ${ }^{1} \mathrm{H}$ and ${ }^{13} \mathrm{C}$ skyline projections.
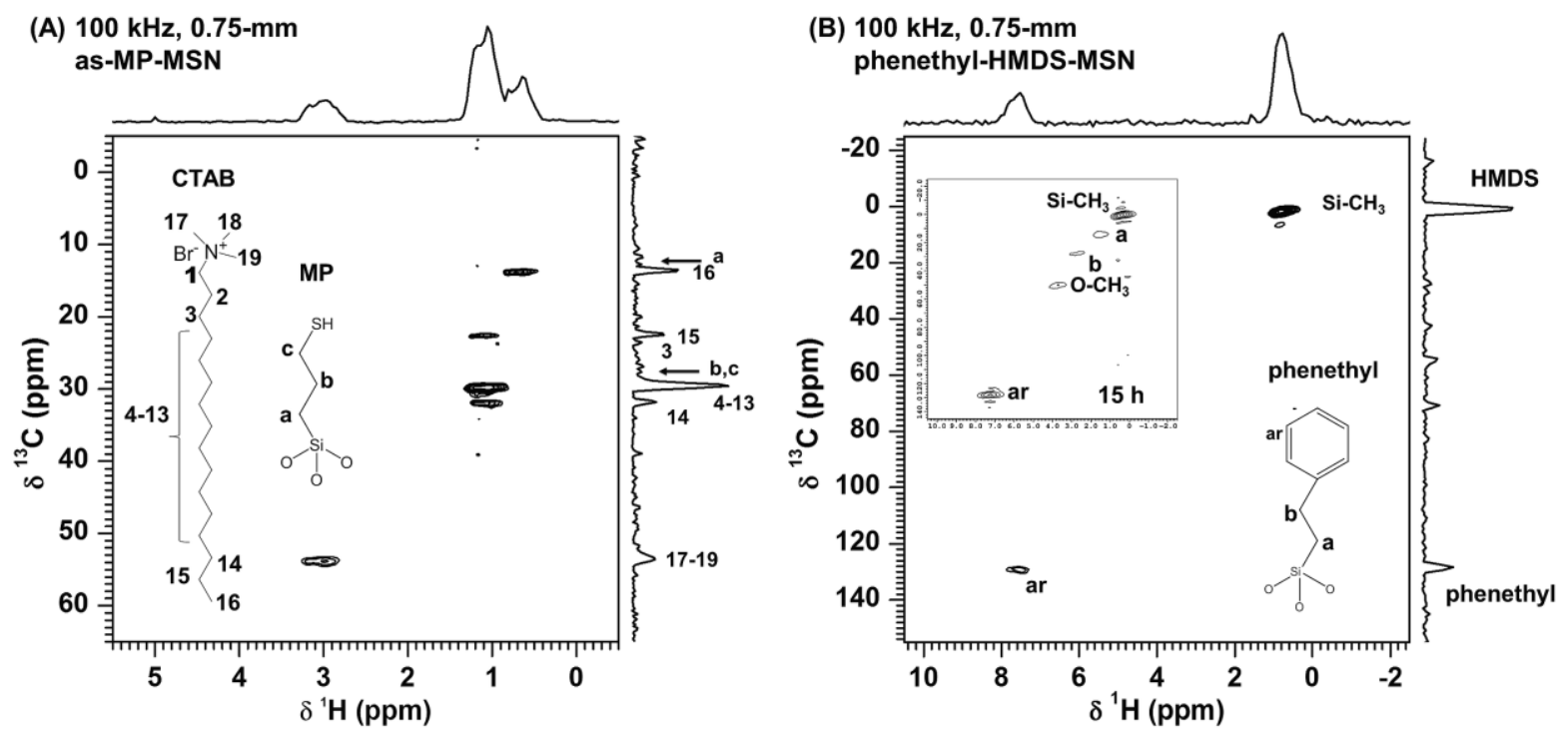

Fig. 4. $2 \mathrm{D}{ }^{1} \mathrm{H}\left\{{ }^{13} \mathrm{C}\right\}$ HMQC-type spectra of (A) as-MP-MSN and (B) phenethyl-HMDS-MSN taken at 
14.1 T under the following conditions: (A) ${ }^{1} \mathrm{H}\left\{{ }^{13} \mathrm{C}\right\}, v_{\mathrm{R}}=100 \mathrm{kHz}$, and $\tau=3 \mathrm{~ms}$; (B) ${ }^{1} \mathrm{H}\left\{{ }^{13} \mathrm{C}\right\}, v_{\mathrm{R}}=100$ $\mathrm{kHz}$ (97 kHz for inset), and $\tau=3 \mathrm{~ms}$. Spectrum (A) was acquired in 256 rows, with $\Delta \mathrm{t}_{1}=4 \mu \mathrm{s}, 8$ scans per row, $\tau_{\mathrm{RD}}=1.35 \mathrm{~s}$, and AT $=1.5 \mathrm{~h}$. Spectrum (B) was acquired in 64 rows, with $\Delta t_{1}=26.48 \mu \mathrm{s}, 2$ scans ( 256 scans for the inset) per row, $\tau_{\mathrm{RD}}=2 \mathrm{~s}(1.7 \mathrm{~s}$ for the inset), and $\mathrm{AT}=8.5 \mathrm{~min}(15.5 \mathrm{~h}$ for the inset). The spectra were processed using the same parameters and are accompanied by equivalent ${ }^{1} \mathrm{H}$ and ${ }^{13} \mathrm{C}$ skyline projections.

In the solid-state HMQC experiments the ${ }^{13} \mathrm{C}^{1}{ }^{1} \mathrm{H}$ transfers can be achieved via $J$ coupling $(J$-HMQC) or dipolar coupling ( $D$-HMQC). Here, we carried out the $J$-HMQC measurements using the pulse sequence shown in Fig. 1B. In addition to providing through-bond filtering, the advantages of the $J$ HMQC over $D$-HMQC include robustness and immunity to the $\mathrm{t}_{1}$-noise problems induced in the indirect dimension $D$-HMQC spectra by the fluctuations of MAS frequency [26]. The main shortcoming of the $J$-HMQC scheme is susceptibility to $T_{2}$ relaxation effects during polarization transfers, each requiring several $\mathrm{ms}(\mathrm{t} \approx 1 / 2 J)$, and during $\mathrm{t}_{1}$ evolution.

Both the benefits and shortcomings of the $J$-HMQC experiment are on display in the spectra of Fig. 4. The transfers involving ${ }^{1} \mathrm{H}$ nuclei with long $T_{2 H}$ times proved to be very efficient. This is evident in the spectrum of as-MP-MSN (Fig. 4A), which features strong resonances representing most of the expected ${ }^{13} \mathrm{C}-{ }^{1} \mathrm{H}$ correlations in $\mathrm{CTAB}$. However, the correlations due to mercaptopropyl groups are notably absent, despite being easily detected in the HSQC spectrum of the same sample after the surfactant had been extracted (Fig. 3).

Similarly, Fig. 4B shows a 2D HMQC spectrum of surface-bound species of the phenethyl-HMDSMSN sample, again containing merely $\sim 10^{16}$ of ${ }^{13} \mathrm{C}-{ }^{1} \mathrm{H}$ pairs, which was measured in less than 9 min. The cross-peaks involving the aromatic group of phenethyl and methyl groups in HMDS, with $T_{2 H}$ of 17 and $26 \mathrm{~ms}$, respectively, were detected with very high efficiency, exceeding $50 \%$ of the intensity of the properly scaled ${ }^{1} \mathrm{H}$ DPMAS spectrum. On the other hand, even at $\nu_{\mathrm{R}}=100 \mathrm{kHz}$ the correlations involving sites with shorter $T_{2 H}$ times were strongly suppressed, and could only be detected after a 
much longer acquisition. Indeed, the methylene groups $\mathbf{a}$ and $\mathbf{b}$ in phenetyl groups, with $T_{2 H}$ values of $11 \mathrm{~ms}$ and $10 \mathrm{~ms}$, respectively, can be recognized in the spectrum of the same sample acquired in $15 \mathrm{~h}$ (see the inset in Fig. 4B).

\section{CONCLUSION}

We demonstrated that high-quality 2D HETCOR ${ }^{1} \mathrm{H}\left\{{ }^{13} \mathrm{C}\right\}$ spectra of natural abundance samples can be conveniently obtained under MAS at $100 \mathrm{kHz}$. Despite the miniature volume of 0.75 -mm MAS rotor, even surface-bound functionalities comprising just $10^{16}$ of ${ }^{13} \mathrm{C}-{ }^{1} \mathrm{H}$ pairs can be studied. The HSQC-type experiments are easy to optimize and yield sensitivity in that comes surprisingly close to that achieved in much larger 1.6-mm rotors capable of MAS at $40 \mathrm{kHz}$. It should be noted, however, that decoherence of

transverse ${ }^{1} \mathrm{H}$ magnetization of strongly coupled spins is generally too fast to allow for similar efficiency in HMQC-type measurements spectra. This shortcoming can be alleviated by using ${ }^{1} \mathrm{H}-{ }^{1} \mathrm{H}$ homonuclear dipolar decoupling.

The ultrafast MAS technology offers high efficiency of heteronuclear polarization transfer, opportunities for spectral editing hitherto limited to solution NMR, and fundamentally new decoupling/recoupling capabilities. These effects institute the gradual convergence of solid-state and solution NMR and lend themselves to further experimental and theoretical investigation. Their applications will include a variety of energy-related materials, including complex hydrides, thermoelectric materials, biological solids and heterogeneous catalysts.

\section{ACKNOWLEDGEMENTS}

This research was supported by the U.S. Department of Energy, Office of Basic Energy Sciences (BES), 
Division of Chemical Sciences, Geosciences, and Biosciences through the Ames Laboratory (T.K., D.S.-

A., I.I.S., M.P.). The Ames Laboratory is operated for the U.S. Department of Energy by Iowa State

University under Contract No. DE-AC02-07CH11358.

\section{REFERENCES}

[1] A. Samoson, Extended magic-angle spinning, in: D.M.R. Grant, K. Harris (Eds.) Encyclopedia of Nuclear Magnetic Resonance, John Wiely \& Sons, Chichester, 2002, pp. 59-64.

[2] L.S. Du, A. Samoson, T. Tuherm, C.P. Grey, F-19/Na-23 double resonance MAS NMR study of oxygen/fluorine ordering in the oxyfluoride Na5W309F5, Chem. Mater. 12 (2000) 36113616.

[3] Y. Nishiyama, Y. Endo, T. Nemoto, H. Utsumi, K. Yamauchi, K. Hioka, T. Asakura, Very fast magic angle spinning H-1-N-14 2D solid-state NMR: Sub-micro-liter sample data collection in a few minutes, J. Magn. Reson. 208 (2011) 44-48.

[4] V. Agarwal, T. Tuherm, A. Reinhold, J. Past, A. Samoson, M. Ernst, B.H. Meier, Amplitudemodulated low-power decoupling sequences for fast magic-angle spinning NMR, Chem. Phys. Lett. 583 (2013) 1-7.

[5] A.R. Palmer, D. Rice, S. Hafner, M. Cormos, FastMAS and UltraFastMAS, Application Notes, Agilent Technologies Inc., Santa Clara, CA, 2007.

[6] J.-P. Demers, V. Chevelkov, A. Lange, Progress in correlation spectroscopy at ultra-fast magicangle spinning: Basic building blocks and complex experiments for the study of protein structure and dynamics, Solid State Nucl. Magn. Reson. 40 (2011) 101-113.

[7] M. Ernst, A. Detken, A. Bockmann, B.H. Meier, NMR spectra of a microcrystalline protein at 30 kHz MAS, J. Am. Chem. Soc. 125 (2003) 15807-15810.

[8] J. Trebosc, J.W. Wiench, S. Huh, V.S.Y. Lin, M. Pruski, Studies of organically functionalized mesoporous silicas using heteronuclear solid-state correlation NMR spectroscopy under fast magic angle spinning, J. Am. Chem. Soc. 127 (2005) 7587-7593.

[9] M. Ernst, A. Samoson, B.H. Meier, Low-power decoupling in fast magic-angle spinning NMR, Chem. Phys. Lett. 348 (2001) 293-302.

[10] M. Ernst, M.A. Meier, T. Tuherm, A. Samoson, B.H. Meier, Low-power high-resolution solidstate NMR of peptides and proteins, J. Am. Chem. Soc. 126 (2004) 4764-4765.

[11] A. Lange, I. Scholz, T. Manolikas, M. Ernst, B.H. Meier, Low-power cross polarization in fast magic-angle spinning NMR experiments, Chem. Phys. Lett. 468 (2009) 100-105.

[12] J.-P. Demers, V. Vijayan, S. Becker, A. Lange, Tailored low-power cross-polarization under fast magic-angle spinning, J. Magn. Reson. 205 (2010) 216-223.

[13] N.P. Wickramasinghe, S. Parthasarathy, C.R. Jones, C. Bhardwaj, F. Long, M. Kotecha, S. Mehboob, L.W.M. Fung, J. Past, A. Samoson, Y. Ishii, Nanomole-scale protein solid-state NMR by breaking intrinsic H-1 T-1 boundaries, Nature Methods 6 (2009) 215-218.

[14] S. Laage, A. Marchetti, J. Sein, R. Pierattelli, H.J. Sass, S. Grzesiek, A. Lesage, G. Pintacuda, L. Emsley, Band-selective H-1-C-13 cross-polarization in fast magic angle spinning solid-state NMR spectroscopy, J. Am. Chem. Soc. 130 (2008) 17216-17217. 
[15] S. Parthasarathy, Y. Nishiyama, Y. Ishii, Sensitivity and resolution enhanced solid-state NMR for paramagnetic systems and biomolecules under very fast magic angle spinning, Acc. Chem. Res. 46 (2013) 2127-2135.

[16] G. Pintacuda, G. Kervern, Paramagnetic solid-state magic-angle spinning NMR spectroscopy, Modern Nmr Methodology 335 (2013) 157-200.

[17] M. Leskes, S. Steuernagel, D. Schneider, P.K. Madhu, S. Vega, Homonuclear dipolar decoupling at magic-angle spinning frequencies up to $65 \mathrm{kHz}$ in solid-state nuclear magnetic resonance, Chem. Phys. Lett. 466 (2008) 95-99.

[18] M. Leskes, P.K. Madhu, S. Vega, Why does PMLG proton decoupling work at $65 \mathrm{kHz}$ MAS?, J. Magn. Reson. 199 (2009) 208-213.

[19] K. Mao, M. Pruski, Homonuclear dipolar decoupling under fast MAS: Resolution patterns and simple optimization strategy, J. Magn. Reson. 203 (2010) 144-149.

[20] X. Lu, O. Lafon, J. Trebosc, A.S.L. Thankamony, Y. Nishiyama, Z. Gan, P.K. Madhu, J.-P. Amoureux, Detailed analysis of the TIMES and TIMES0 high-resolution MAS methods for high-resolution proton NMR, J. Magn. Reson. 223 (2012) 219-227.

[21] Y. Ishii, R. Tycko, Sensitivity enhancement in solid state N-15 NMR by indirect detection with high-speed magic angle spinning, J. Magn. Reson. 142 (2000) 199-204.

[22] B. Reif, R.G. Griffin, H-1 detected H-1, N-15 correlation spectroscopy in rotating solids, J. Magn. Reson. 160 (2003) 78-83.

[23] D.H. Zhou, G. Shah, M. Cormos, C. Mullen, D. Sandoz, C.M. Rienstra, Proton-detected solid-state NMR Spectroscopy of fully protonated proteins at $40 \mathrm{kHz}$ magic-angle spinning, J. Am. Chem. Soc. 129 (2007) 11791-11801.

[24] K. Mao, J.W. Wiench, V.S.Y. Lin, M. Pruski, Indirectly detected through-bond chemical shift correlation NMR spectroscopy in solids under fast MAS: Studies of organic-inorganic hybrid materials, J. Magn. Reson. 196 (2009) 92-95.

[25] T. Kobayashi, K. Mao, P. Paluch, A. Nowak-Krol, J. Sniechowska, Y. Nishiyama, D.T. Gryko, M.J. Potrzebowski, M. Pruski, Study of Intermolecular Interactions in the Corrole Matrix by SolidState NMR under $100 \mathrm{kHz}$ MAS and Theoretical Calculations, Angew. Chem. Int. Ed. 52 (2013) 14108-14111.

[26] Y. Nishiyama, X. Lu, J. Trebosc, O. Lafon, Z. Gan, P.K. Madhu, J.-P. Amoureux, Practical choice of $\mathrm{H}-1-\mathrm{H}-1$ decoupling schemes in through-bond $\mathrm{H}-1-\{\mathrm{X}\}$ HMQC experiments at ultra-fast MAS, J. Magn. Reson. 214 (2012) 151-158.

[27] Y.Q. Ye, M. Malon, C. Martineau, F. Taulelle, Y. Nishiyama, Rapid measurement of multidimensional H-1 solid-state NMR spectra at ultra-fast MAS frequencies, J. Magn. Reson. 239 (2014) 75-80.

[28] V. Agarwal, S. Penzel, K. Szekely, R. Cadalbert, E. Testori, A. Oss, J. Past, A. Samoson, M. Ernst, A. Boeckmann, B.H. Meier, De Novo 3D Structure Determination from Sub-milligram Protein Samples by Solid-State 100 kHz MAS NMR Spectroscopy, Angew. Chem. Int. Ed. 53 (2014) 12253-12256.

[29] K. Kandel, S.M. Althaus, C. Peeraphatdit, T. Kobayashi, B.G. Trewyn, M. Pruski, I.I. Slowing, Substrate inhibition in the heterogeneous catalyzed aldol condensation: A mechanistic study of supported organocatalysts, J. Catal. 291 (2012) 63-68.

[30] G. Bodenhausen, D.J. Ruben, Natural abundance N-15 NMR by enhanced heteronuclear spectroscopy, Chem. Phys. Lett. 69 (1980) 185-189.

[31] A. Bax, R.H. Griffey, B.L. Hawkins, Correlation of proton and N-15 chemical-shifts by multiple quantum NMR, J. Magn. Reson. 55 (1983) 301-315. 
[32] K. Mao, M. Pruski, Directly and indirectly detected through-bond heteronuclear correlation solid-state NMR spectroscopy under fast MAS, J. Magn. Reson. 201 (2009) 165-174.

[33] B.H. Meier, Cross polarization under fast magic angle spinning - thermodynamical considerations, Chem. Phys. Lett. 188 (1992) 201-207.

[34] B.M. Fung, A.K. Khitrin, K. Ermolaev, An improved broadband decoupling sequence for liquid crystals and solids, J. Magn. Reson. 142 (2000) 97-101.

[35] A.J. Shaka, J. Keeler, T. Frenkiel, R. Freeman, An improved sequence for broad-band decoupling - WALTZ-16, J. Magn. Reson. 52 (1983) 335-338.

[36] Y. Ishii, J.P. Yesinowski, R. Tycko, Sensitivity enhancement in solid-state C-13 NMR of synthetic polymers and biopolymers by H-1 NMR detection with high-speed magic angle spinning, J. Am. Chem. Soc. 123 (2001) 2921-2922.

[37] J.W. Wiench, C.E. Bronnimann, V.S.Y. Lin, M. Pruski, Chemical shift correlation NMR spectroscopy with indirect detection in fast rotating solids: Studies of organically functionalized mesoporous silicas, J. Am. Chem. Soc. 129 (2007) 12076-12077.

[38] P. Paluch, T. Pawlak, J.-P. Amoureux, M.J. Potrzebowski, Simple and accurate determination of X-H distances under ultra-fast MAS NMR, J. Magn. Reson. 233 (2013) 56-63.

[39] T.L. Peck, R.L. Magin, P.C. Lauterbur, Design and analysis of microcoils for NMR microscopy, J. Magn. Reson. B 108 (1995) 114-124.

[40] J.D. Kraus, Electromagnetics, McGraw-Hill, New York, 1953.

[41] C.M. Rienstra, L. Tucker-Kellogg, C.P. Jaroniec, M. Hohwy, B. Reif, M.T. McMahon, B. Tidor, T. Lozano-Perez, R.G. Griffin, De novo determination of peptide structure with solid-state magic-angle spinning NMR spectroscopy, Proc. Natl. Acad. Sci. U. S. A. 99 (2002) 1026010265.

[42] V.S. Bajaj, P.C.A. van der Wel, R.G. Griffin, Observation of a Low-Temperature, Dynamically Driven Structural Transition in a Polypeptide by Solid-State NMR Spectroscopy, J. Am. Chem. Soc. 131 (2009) 118-128.

[43] S. Huh, J.W. Wiench, J.C. Yoo, M. Pruski, V.S.Y. Lin, Organic functionalization and morphology control of mesoporous silicas via a co-condensation synthesis method, Chem. Mater. 15 (2003) 4247-4256. 